Short Communication

\title{
UNCO VERTEBRAL JOINTS OF LUSCHKA: AN OSTEOLOGICAL STUDY
}

\author{
Remya K., Arunachalam Kumar, Vishal Kumar. \\ K.S. Hegde M edical Academy, Nitte University, Derlakatte, M angalore - 575 018. INDIA \\ Correspondence: \\ Remya K. \\ Department of Anatomy, K.S. Hegde M edical Academy, Nitte University, Derlakatte, Mangalore - 575 018. INDIA \\ Mobile : +919916808842 E-mail : remya_285@yahoo.co.in
}

\begin{abstract}
:
Uncus or uncinate process is flange-like lip which arises from most of the lateral circumference of the upper margin of the vertebral body. It ossifies from neural arch of vertebrae. These are commonly found in lower five cervical vertebrae. The area between the periphery of intervertebral disc and uncus is occupied by loose fibrous tissue. When this fibrous tissue resorbs it leaves a space that constitutes Luschka's joint. These joints are well developed and larger in the mid to lower cervical region and smaller joints appear in the most cranial and caudal levels. We have found total of 23 such type of articular facets, on both upper and lower surfaces. These joints are clinically important because of its relationship with vessels and nerves. M any of the neurological symptoms of the arm, neck and back of the head are related to these accomadative joints
\end{abstract}

Keywords: Uncus, Cervical vertebra, Luschka'sjoint.

\section{Introduction:}

"Von Luschka" in 1858 was first one to give accurate and detailed description of the uncovertebral joint. Different authors like Girudi, Trolard, Turner, Frykholam have described this joint under different names $(1,3)$

Uncus is the bony projection on the lateral margin of upper surface of the bodies of lower five cervical vertebra $(2,3,5)$ The lateral part of inferior surface of the body facing the medial surface of the uncus is slightly concave $(2,3)$ and is covered by cartilage. Articulations between these two surface is called Luschka's joint. This prominence is also present in the upper surface of the body of first thoracic vertebrae (2,6) ( Figures: 1,2,3)

These joints are located anteromedial to mixed nerve root and posteromedial to vertebral vessels and sympathetic nerve fibers.(1) Well Access this article online developed larger joints are observed in the mid to lower cervical (C3- C7) regions and smaller joints appear in the most cranial and caudal (C2-C3, C7T1)levels. (6)
These uncinate processes are easily seen in anteroposterior roentgenogram of typical cervical vertebra (3) (Figure: 4)

Three ossification centers appear for each vertebra: one for the vertebral body and two for the neural arch. Uncus ossifies from ossification center for neural arch. In cervical region part of the neural arch forming uncus is not on the same transverse plane as the body but is cephalad to it. In other regions of the vertebra, ossification centers for body and arch are at same transverse plane. $(2,7)$

Uncinate processes guide and control the anteroposterior translation which occurs during sagittal motion (4)

Like other joints osteophytes and osteochondrosis can develop in this joint. Clinicians keep in mind about this less studied joint while diagnosing (3)

\section{Materials and methods:}

We have selected 40 number of adult cervical vertebra of unknown sex which are available in our practical laboratory (excluding damaged ones). We have observed both superior and inferior surface of the body and noted those articular facets. 


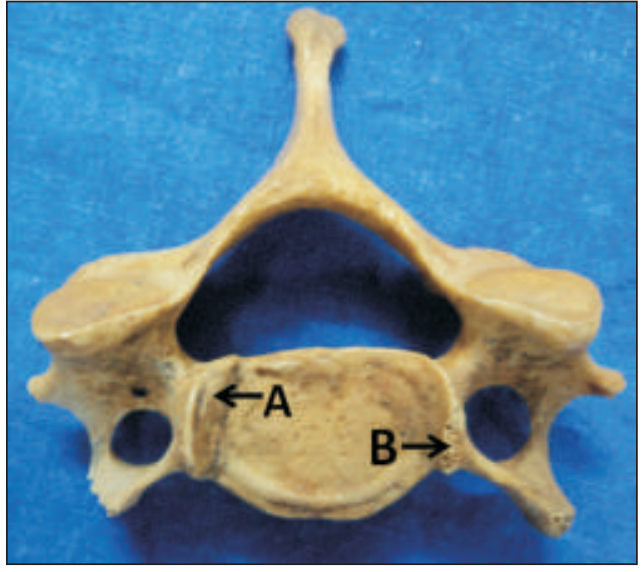

Figure 1. Superior surface of cervical vertebra showing A- Uncus. B- Articular facet.

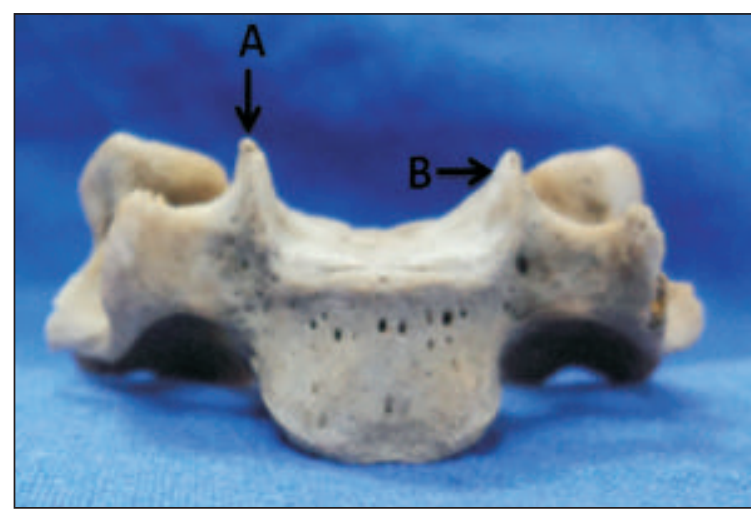

Figure 3. Anterior surface of cervical vertebra showing AUncus, B- Articulating facet.

\section{Observation:}

Among 40 vertebra studied we found articular facets on the medial surface of uncus in 18 vertebrae among these 9 of them had the facet on right, 5 had on left $\& 4$ had facets on both sides.

\begin{tabular}{|c|c|c|c|}
\hline S. No. & Side & Number & $\%$ \\
\hline 1 & Right & 9 & 22.5 \\
\hline 2 & Left & 5 & 12.5 \\
\hline 3 & Both & 4 & 10 \\
\hline
\end{tabular}

Table 1: Articular facets on medial surface of uncus.

Out of the 40 vertebra studied articular facets were found on the infero lateral part of the body in 11 vertebrae among these 6 of them had the facet on right, 3 had on left $\& 2$ had facets on both sides.

\begin{tabular}{|c|c|c|c|}
\hline S. No. & Side & Number & $\%$ \\
\hline 1 & Right & 6 & 15 \\
\hline 2 & Left & 3 & 7.5 \\
\hline 3 & Both & 2 & 5 \\
\hline
\end{tabular}

Table. 2: Articular facets on inferolateral part of the body.

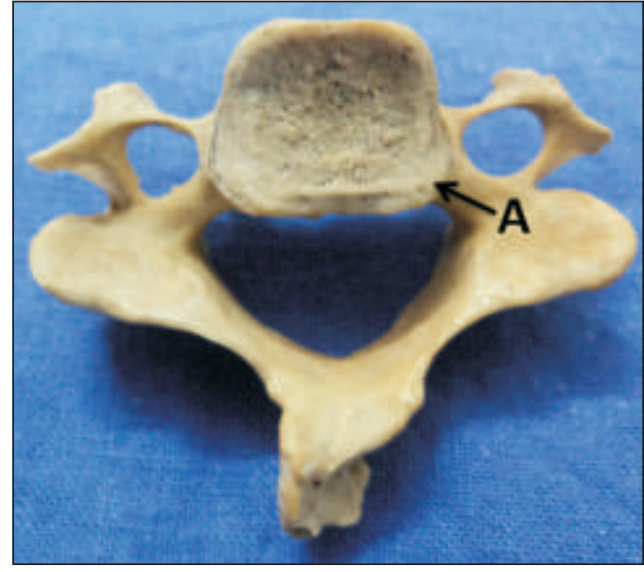

Figure 2. Superior surface of cervical vertebra showing A-Beveled inferolateral surface.

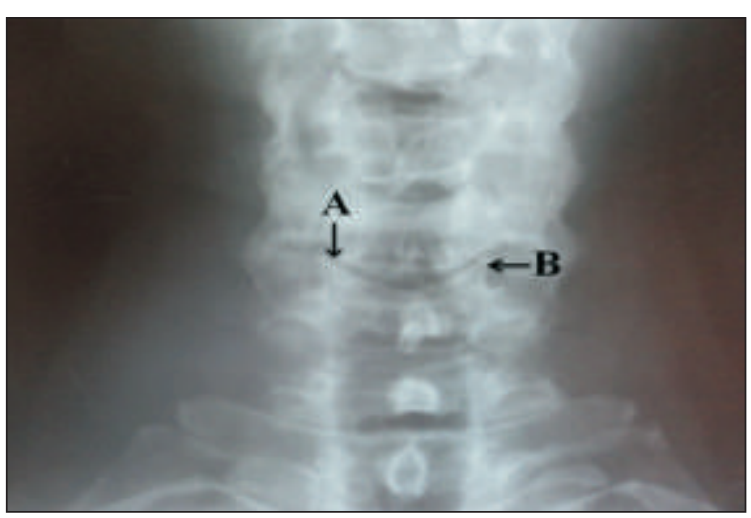

Figure 4. Anteroposterior view of $\mathrm{x}$-ray of neck showing A- Uncus, B- Uncovertebral joint.

\section{Discussion:}

Frykholm and Hall proposed their theories about the function of uncus, but none of them are able to explain the formation of uncus. According to Tonduny as well as Sherk and Parke described the uncus belonging to the neural arch, but they were not clear about its origin. Hayashi K, Yabuki T. in 1985 studied a specimen of fourth cervical vertebra from seven year old boy. They found that junction between developing body and neural arch gives raise to uncus. (2) We also observed bony projection uncus is located between body and pedicle of cervical vertebrae.

Payne and Spillane, Onofino et al., and Hirsch et al., thought this joint as a degenerative change. Boreadis and Gershon Cohen, stated it to be a true joint, but did not describe how it is formed. Frykholm said that this joint is part of the intervertebral disc. But Orofino et al., Hall, and Tonduny stated that, some of the loose fibrous tissues 
present at birth or during the fetal period that has different character than the disc tissue is found in the area is absorbed and develops into Luschka's joint. Hayashi K, Yabuki T. described this by microscopic study of sliced fetal spine. (2)

Turner described typical cervical vertebra with two well marked lateral lips on the upper surface and beveled inferior surface laterally. Both these surfaces rest against each other to form a joint. These lateral lips or uncus is easily seen in antero-posterior roentgenogram of typical cervical vertebra (3). Turner proceeds to describe the superior vertebral notch is deeper than inferior because of this joint located antero-medially, which can be seen in oblique roentgenogram. (3)

Uncovertebral joints are small synovial joints measuring $2 \times 4$ to $3 \times 6 \mathrm{~mm}$., situated between the bodies lower five cervical vertebra. These are related to mixed nerve roots antero-medially and postero-medially to vertebral artery, vein and sympathetics. (1)

Three dimensional study of joint is done by obtaining sequential cryo-sectioning of the specimens in all three axes and measuring them by obtaining good quality of magnified images by Kumaresan $S$ and his colleague. They found that these synovial joints are located between C2-T1 vertebrae bilaterally. They found no any statistically significant difference between right and left side. Joint is located more ventrally in mid and lower (C3- C7) cervical region compared to cranial (C2-C3) and caudal (C7-T1) (6).

Uncovertebral joints control the anteroposterior translation which occurs during sagittal motion in the neck confirmed by five linear and two angular measurements on each cervical vertebra. (4)

\section{References:}

1. Boreadis A G and Gershon-Cohen J. Luschka Joints of the Cervical Spine. Radiology, 1956; 66:181-87

2. Hayashi K, Yabuki T. Origin of the Uncus and Of Luschka's Joint in the Cervical Spine. The Journal of bone and Joint Surgery, 1985;67-A(5) :788-91.

3. Lyon E. Uncovertebral osteophytes and osteochondroses of the cervical spine. The Journal of bone and Joint Surgery, 1945 ; XXVII(2) :248-53.

4. Silberstein C.E. The evolution of degenerative changes in the cervical spine and an investigation into the "joints of Luschka".Clin Orthop Relat Res, 1965;40:184-204.

5. Standring S, Gray's Anatomy, $40^{\text {th }} \mathrm{Ed}, 2008$, pp 718, Elsevier publishers London.

6. Kumarean S, Yoganandan N, Pintar A F, Larson J S, Sances A, Frontiers in Head and Neck trauma, 1998, pp 34-41, IOS press, Netherland.

7. Vishram Singh, Text book of Clinical Embryology,2012, pp 87-90, Elsevier publishers New Dehli. 